\title{
Does monetary integration lead to income convergence in Africa? a study of the CFA monetary area
}

\author{
Souleymane Ndao ${ }^{1}$ \& Nikolay Nenovsky ${ }^{1,2}$ \& Kiril Tochkov ${ }^{3}$
}

Received: 9 February 2017 / Accepted: 17 October 2018 / Published online: 3 December 2018 \# ISEG 2018

\begin{abstract}
The CFA franc area is one of the oldest currency unions, but it has come under intense criticism recently for failing to promote economic growth and income convergence between member states. This paper examines the growth experience of the 14 member countries relative to a common benchmark over the period 1960-2011. In particular, we use a combination of parametric and non-parametric methods to study convergence patterns as well as growth dynamics and to identify the factors responsible for changes in relative per-capita income. The results indicate divergence tendencies that result in a bimodal distribution in the long run. The sharp devaluation of the CFA franc in 1994 increases intradistributional mobility which is directed towards lower income levels. The regression analysis suggests that openness, FDI, and financial development have a positive and robust effect on convergence in the currency union.
\end{abstract}

Keywords African monetary integration $\cdot$ CFA zone $\cdot$ Convergence $\cdot$ Growth factors

JEL classification $\mathrm{F} 45 \cdot \mathrm{O} 47 \cdot \mathrm{O} 55$

* Souleymane Ndao ndaosouleymane@hotmail.fr

1 University of Picardie Jules Verne, CRIISEA, Amiens, France

2 RUDN University, Faculty of Economics, Moscow, Russia

3 Texas Christian University, Texas, USA 